\title{
Transliteration Note
}

In the main body of the text, the transliteration of Russian names has been simplified with a view to making them easier on the Anglophone reader's eyes (hence, for example, Yury Brodsky rather than Iurii Brodskii). Likewise, where established conventional English spellings of particular names and place names exist, these have been given preference (hence, for example, Mandelstam, not Mandel'shtam). In the footnotes and bibliography, Russian names and sources have been transliterated according to the Library of Congress system. The acronym for Gosudarstvennoe upravlenie lagerei (State Administration of Camps) should be rendered as "GULag," but I have opted to spell this word "gulag" and understand it in a broader meaning. All translations are mine unless stated otherwise. 
